\title{
Vitamin D Status in Children with Idiopathic Dilated Cardiomyopathy
}

\author{
Duaa M. Raafat ${ }^{1} \quad$ Osama M. EL-Asheer ${ }^{1}$ Amal A. Mahmoud ${ }^{2} \quad$ Manal M. Darwish $^{3}$ Naglaa S. Osman ${ }^{1}$ \\ ${ }^{1}$ Department of Pediatrics, Children's Hospital, Faculty of Medicine, \\ Assiut University, Assiut, Egypt \\ 2 Department of Clinical Pathology, Faculty of Medicine, Assiut \\ University, Assiut, Egypt \\ Address for correspondence Osama M. EL-Asheer, MD, Department \\ of Pediatrics, Faculty of Medicine, Assiut University Children Hospital, \\ Assiut University, Assiut 71515, Egypt \\ (e-mail: asheer1970@aun.edu.eg; asheer1970@gmail.com).
}

${ }^{3}$ Department of Public Health and Community Medicine, Faculty of Medicine, Assiut University, Assiut, Egypt

J Child Sci 2021;11:e120-e124.

\begin{abstract}
\section{Keywords}

- vitamin D

- children

- dilated cardiomyopathy

Dilated cardiomyopathy (DCM) is the third leading cause of heart failure in pediatrics. The exact etiology of DCM is unknown in more than half of the cases. Vitamin D receptors are represented in cardiac muscles, endothelium, and smooth muscles of blood vessels suggesting that vitamin $D$ could have a vital cardioprotective function. This study aimed to assess serum level of vitamin D in children with idiopathic DCM and to correlate the serum level of vitamin $\mathrm{D}$ with the left ventricular dimensions and function. This study is a descriptive cross-sectional single-center study, includes 44 children of both sexes, diagnosed as idiopathic DCM. Serum level of vitamin D was assessed and correlated with the left ventricular dimensions and function. Mean age of studied children was $6.08 \pm 4.4$ years. Vitamin D deficiency was found in $90.9 \%$ of children with idiopathic DCM with a mean level $13.48 \mathrm{ng} / \mathrm{mL}$. There was a negative correlation between vitamin D level and fraction shortening and left ventricular enddiastolic diameter in children with DCM. Vitamin D level is not only significantly low in children with idiopathic DCM but it is also significantly correlated with the degree of left ventricular dysfunction.
\end{abstract}

\section{Introduction}

Dilated cardiomyopathy (DCM) is the third leading cause of heart failure in pediatrics. ${ }^{1}$ World Health Organization defined it as "dilatation and impaired contraction of the left or both ventricles with normal wall thickness." ${ }^{2}$ The likely prevalence of DCM in children is ranging from 1 in 140,000 to $170,000 .^{3}$

The exact etiology of DCM is unknown in more than half of the cases and the term idiopathic DCM is used after exclusion of all the well-known etiologies of DCM as viral infections, autoimmune, genetic, endocrinal, and metabolic diseases. ${ }^{1,4}$

Vitamin D is a hormone that has a well-known function in the maintenance of a healthy skeletal system. Recently, new

received

January 1, 2021

accepted after revision

April 7, 2021
DOI https://doi.org/

10.1055/s-0041-1731076.

ISSN 2474-5871. other emerging roles of vitamin D were supposed, taking in consideration the widespread existence of vitamin D receptors (VDRs) in different body tissues. ${ }^{5}$

VDRs exist in cardiac muscles, endothelium, and smooth muscles of blood vessels. ${ }^{6}$ Signals from the interaction between vitamin $\mathrm{D}$ and its receptors modulate gene expression $^{7}$ and have antihypertrophic action on cardiac muscles, ${ }^{8}$ suggesting that vitamin $\mathrm{D}$ could have a vital cardioprotective function. ${ }^{5,6}$

One of the suggested treatable causes of DCM is hypocalcemia that could be due to low level of vitamin D., ${ }^{9,10}$ Calcium has essential cardiotonic effect through being vital for the excitation of cardiac muscle, and its deficiency adversely

\section{(c) 2021. The Author(s).}

This is an open access article published by Thieme under the terms of the Creative Commons Attribution License, permitting unrestricted use, distribution, and reproduction so long as the original work is properly cited. (https://creativecommons.org/licenses/by/4.0/)

Georg Thieme Verlag KG, Rüdigerstraße 14, 70469 Stuttgart, Germany 
affects myocardial contractility. ${ }^{11}$ This type of DCM responds well to medical treatment with calcium and vitamin D. ${ }^{10,12}$

Despite advances in the management of heart failure, DCM patients still suffer from high morbidity and mortality. ${ }^{7}$

Low level of vitamin $D$ was observed in patients with heart failure, ${ }^{13}$ and it contributes in the pathogenesis of heart failure through its action on the L-type voltage-dependent calcium channels in the cardiomyocyte. ${ }^{14-16}$ Also, vitamin D deficiency is considered a bad prognostic factor that increases the risk of cardiovascular diseases. ${ }^{17,18}$ That is why it is very exciting to find a simple intervention that could be added to the traditional treatment of heart failure and help in the improvement of cardiac function. ${ }^{7}$

Yeşilbaş and Epçaçan in 2019 reported that DCM due to hypocalcemic ricket is curable and has better prognosis than other forms of idiopathic DCM. ${ }^{19}$

The aim of this study is to assess the serum level of vitamin D in children with idiopathic DCM and to correlate their serum level of vitamin D with their left ventricular dimensions and function.

\section{Methods}

\section{Study Design}

A descriptive cross-sectional single-center study was performed. It was conducted on children with idiopathic DCM that were followed up in the Pediatric Cardiology Clinic, Assiut Children's Hospital, Egypt from August 2018 to July 2019.

\section{Study Population and Data collection}

The study included 44 children of both sexes, they were diagnosed as idiopathic DCM after exclusion of recent infections, metabolic, genetic, endocrine, and autoimmune diseases. Patients with chronic diseases such as renal or liver diseases, malabsorptive states, or on any immunosuppressive or anticonvulsant medications were also excluded from the study.

- For all patients, any preceding viral illness or symptoms suggestive of any other systemic affection were assessed; full clinical examinations with complete cardiac examination and echocardiographic evaluation to measure fraction shortening (FS), left ventricular end-diastolic diameter (LVEDD), and left ventricular end-systolic diameter (LVESD) were performed.

- Blood investigations including routine work-up for newly diagnosed case of DCM such as complete blood count, metabolic profile (arterial blood gases, liver and kidney function test, electrolytes, calcium, magnesium, phosphorus), parathyroid hormone, random blood glucose, thyroid function test, erythrocyte sedimentation rate, and C-reactive protein level, in addition to creatine phosphokinase level, lactate dehydrogenase level, and $25(\mathrm{OH})$ vitamin D were assessed.

\section{Echocardiographic Evaluation}

- Transthoracic two-dimensional-M-mode echocardiography was done for each subject. Echocardiography was performed with equipment (2003 Philips EnVisor series,
North America) using a 3- to 6-MHz probe. Images were acquired in subcostal, apical, long axis parasternal, short axis (base and chambers), and suprasternal area. All values, dimensions, and color and Doppler flow velocities were assessed. The same cardiologist who was blinded to patient data established complete echocardiographic evaluation of the patients.

- Data were in accordance with the recommendation of the chamber quantification. Left ventricular FS was computed in all study subjects. Left ventricular ejection fraction (LVEF) was calculated by the Simpson's method in all study subjects. Endocardial borders of the left ventricle were traced from apical four-chamber view during end diastolic and end systolic, then the software automatically estimated the LVEF. $^{20}$

\section{Laboratory Investigations}

- Two $\mathrm{mL}$ of blood was withdrawn by venipuncture and stored in aliquots at $-20^{\circ} \mathrm{C}$ to measure vitamin D levels.

- Serum $25(\mathrm{OH})$ vitamin D level was measured by the competitive enzyme-linked immunosorbent assay technique using a Calbiotech kit (a life science company, catalogue no: VD220B, San Diego-based company established in 1998, United States).

\section{Reference Range of Serum 25(OH) Vitamin D Level}

The reference range of serum $25(\mathrm{OH})$ vitamin $\mathrm{D}$ level is as follows: ${ }^{21-23}$

- Severe deficiency: $\leq 10 \mathrm{ng} / \mathrm{mL}$

- Deficiency: $\leq 20 \mathrm{ng} / \mathrm{mL}$

- Insufficiency: $>20-<30 \mathrm{ng} / \mathrm{mL}$

- Sufficiency: $\geq 30 \mathrm{ng} / \mathrm{mL}$.

\section{Statistical Analysis}

Statistical analyses were performed using the Statistical Package for Social Sciences, version 16.0 (SPSS Inc., Chicago, Illinois, United States). Data are expressed as mean \pm standard deviation for continuous variables or as numbers and percentages for categorical variables. Correlation between variables was done by Spearman-Pearson's correlation test. Probability $(p)$-value $<0.05$ is considered statistically significant.

\section{Results}

- Table 1 shows sociodemographic characteristics of children with idiopathic DCM. - Table 2 shows echocardiographic findings of children with idiopathic DCM. - Fig. 1 shows distribution of vitamin D levels among children with idiopathic DCM. - Fig. 2 shows correlation between vitamin D level and FS. - Fig. 3 shows correlation between vitamin D level and LVEDD.

\section{Discussion}

Despite abundance of sunlight in Middle East and Egypt, studies that assessed vitamin D status revealed high prevalence of vitamin $D$ deficiency and insufficiency that could be attributed to being with darker skin, nutritional factors, and 
Table 1 Sociodemographic characteristics of children with idiopathic DCM

\begin{tabular}{|l|l|l|}
\hline Characteristic & No. (44) or mean \pm SD & $\%$ \\
\hline Age (y) & $6.08 \pm 4.4$ & \\
\hline Mean \pm SD & $5(0.7-14)$ & 36.4 \\
\hline Median (range) & \multicolumn{2}{l|}{} \\
\hline Gender & 16 & 63.6 \\
\hline Male & 28 & 63.6 \\
\hline Female & \multicolumn{2}{|l}{} \\
\hline Residence & 28 & 36.4 \\
\hline Rural & 16 &
\end{tabular}

Abbreviations: DCM, dilated cardiomyopathy; No., number; SD, standard deviation.

Table 2 Echocardiographic findings of children with idiopathic DCM

\begin{tabular}{|l|l|l|}
\hline & No. & Mean \pm SD \\
\hline FS $(\mathrm{mm})$ & 42 & $16.9 \pm 3.8$ \\
\hline LA $(\mathrm{mm})$ & 32 & $25.4 \pm 9$ \\
\hline LVEDD $(\mathrm{mm})$ & 36 & $53.7 \pm 11.0$ \\
\hline LVESD $(\mathrm{mm})$ & 36 & $44.5 \pm 9.6$ \\
\hline TR $($ PG mmHg) & 38 & $25.5 \pm 18.3$ \\
\hline MR grade & No. & $\%$ \\
\hline 1 & 4 & 10.5 \\
\hline 2 & 14 & 36.8 \\
\hline 3 & 8 & 21.1 \\
\hline 4 & 12 & 31.6 \\
\hline
\end{tabular}

Abbreviations: DCM, dilated cardiomyopathy; FS, fraction shortening; LA, left atrium; LVEDD, left ventricular end-diastolic diameter; LVESD, left ventricular end-systolic diameter; MR, mitral regurgitation; No., number; SD, standard deviation; TR, tricuspid regurgitation.

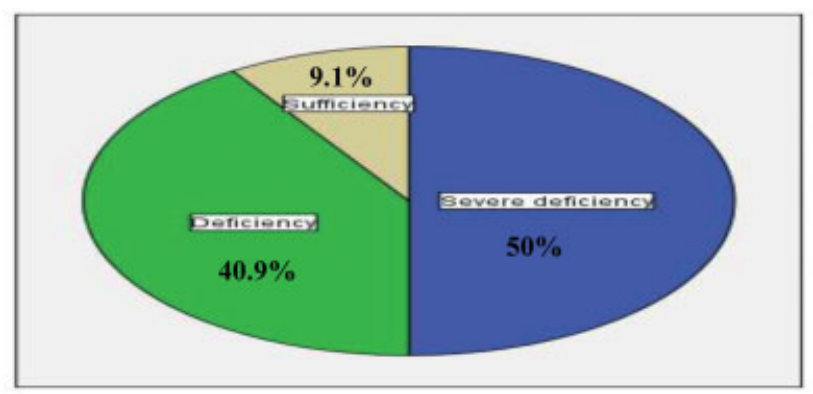

Fig. 1 Distribution of vitamin D levels among children with idiopathic dilated cardiomyopathy (DCM). Vitamin D level is severely deficient in $50 \%$, deficient in $40.9 \%$, and sufficient in $9.1 \%$ of studied children with idiopathic DCM. DCM, dilated cardiomyopathy.

cultural and traditional issues. ${ }^{24,25}$ While in children with heart failure, it can be explained by decreased sunlight exposure with reduced outdoor activities and recumbent position together with defective absorption of vitamin $\mathrm{D}$ due to edema affecting intestinal wall. ${ }^{26}$

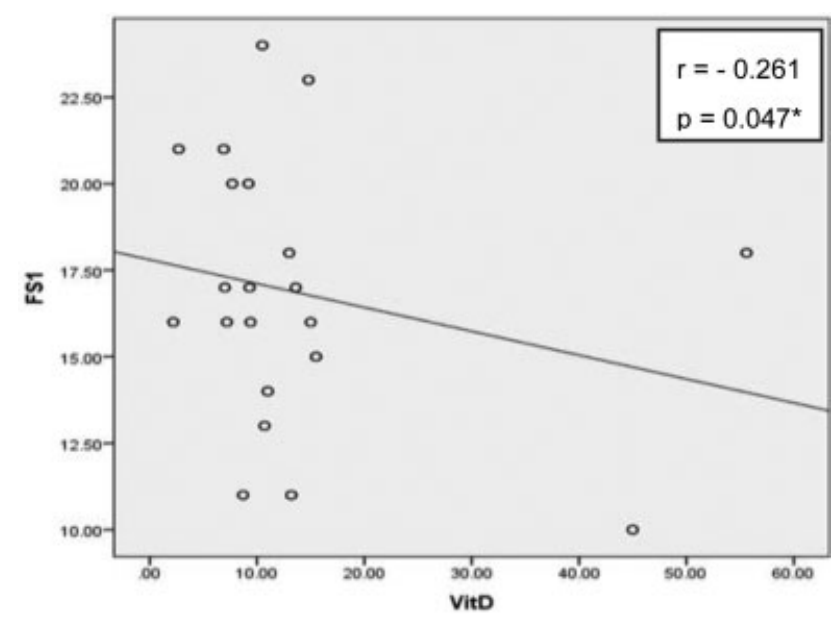

Fig. 2 Correlation between vitamin D level and fraction shortening (FS).

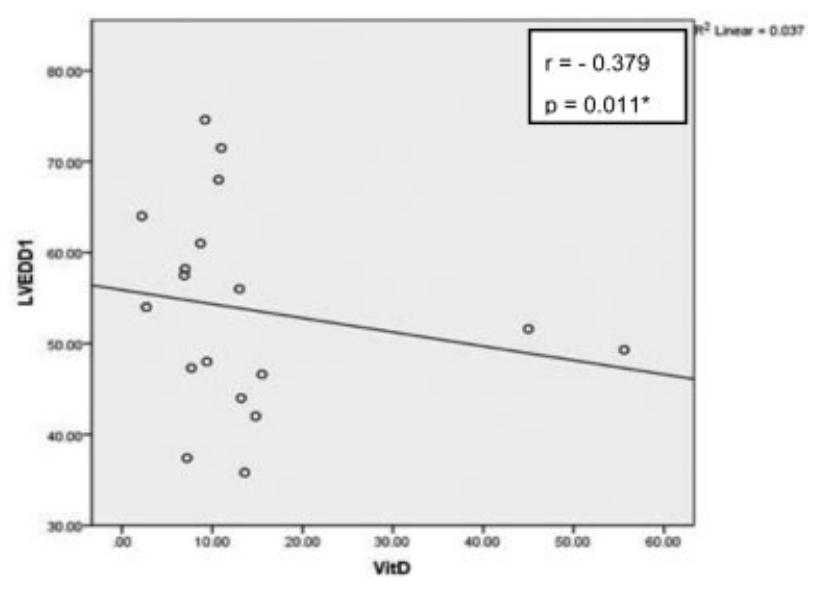

Fig. 3 Correlation between vitamin $D$ level and left ventricular enddiastolic diameter (LVEDD). - Fig. 2 and this figure showed significant negative correlations between vitamin D level, and FS and LVEDD, respectively, in children with idiopathic dilated cardiomyopathy.

Deficiency and insufficiency of vitamin D are observed in toddlers and young-aged Egyptian children. Abu Shady et al in 2016 observed that vitamin D less than $20 \mathrm{ng} / \mathrm{mL}$ was seen in $11.5 \%$ of healthy Egyptian school-aged children, while vitamin D insufficiency ( $>20$ and $<29.9 \mathrm{ng} / \mathrm{mL}$ ) was observed in $15 \%{ }^{25}$ Our study showed that vitamin D deficiency was highly prevalent (up to 90.1\%) among children with idiopathic DCM and 9.1\% was with sufficient $25(\mathrm{OH})$ vitamin D level, and this observation could raise the attention toward the possible contributing role of vitamin deficiency in the pathogenesis of idiopathic DCM.

This study revealed a negative correlation between vitamin D level and FS, as well as with LEVDD of children with DCM. These results were in concordance with a previous case-control study conducted by Priya et al in 2016, who found a significant low vitamin D level in patients with DCM when compared with controls, who were actually patients with other medical disorders. Also, they observed a significant negative correlation between vitamin D level, LVEDD, and LVESD. ${ }^{14}$ Similar findings were reported by Ameri et al, who reported that vitamin $\mathrm{D}$ level had inverse relation with LVESD and LV volume in patients with heart failure. ${ }^{27}$ 
Previously, several case reports and case series of pediatric patients with what is known as rachitic DCM have been reported, and they revealed dramatic improvement after vitamin D supplementation. Fuster et al in 1983 described the first case with rachitic cardiomyopathy. ${ }^{28}$ Also two Turkish cases were reported, one was a female patient aged 9 months, ${ }^{29}$ and the other was a male patient aged 15 months, ${ }^{30}$ both had idiopathic DCM and symptoms of heart failure together with signs of vitamin D deficient rickets, and within 3 months of treatment by vitamin $D$, their cardiac functions were markedly improved.

Retrospectively over 6 years, Maiya et al in 2008 found vitamin D deficiency in 16 patient with DCM, nearly onethird of them died with heart failure. ${ }^{31}$ In 2009, a study of 47 DCM cases found 4 of them with rachitic symptoms, who were cured with vitamin D supplementation in addition to the anticongestive and inotropic medications. ${ }^{32}$ Eren et al in 2015 have reported a case of 3 months old child with idiopathic DCM and his echo showed dilated left ventricle and hypokinetic myocardium with FS 20\%. His cardiac function dramatically improved after receiving calcium lactate and vitamin D. ${ }^{10}$ Interestingly, Yilmaz et al described eight infants with DCM and heart failure who were also due to hypocalcemia and nutritional rickets. ${ }^{11}$

Jammal Addin et al in 2019 conducted a study to assess the etiology and the outcome of children with DCM, showing that $13.2 \%$ of the studied patients were with severe vitamin D deficiency, most of them recovered completely with oral vitamin D supplementation, confirming the reversible nature of this type of cardiomyopathy with prompt early treatment. ${ }^{33}$

The same observation was recorded in adults as well as in pediatrics. Some patients with hypoparathyroidism after surgical thyroidectomy complained of heart failure that was reversible with vitamin D supplementation. ${ }^{34}$ The VINDICATE (VitamIN D treatIng patients with Chronic heArT failurE) trial revealed that high dose of vitamin $\mathrm{D}(4,000 \mathrm{IU})$ in addition to the conventional medical treatment in adult patients with chronic heart failure and vitamin $\mathrm{D}$ deficiency markedly improved their EF by $8 \%{ }^{35}$

\section{Study Limitations}

DCM mainly related to genetic causes, postviral myocarditis, arrhythmias, hypertension, ischemia, etc. Vitamin D deficiency may be a contributing factor, but if it is possible cardiac functions of patients should be re-evaluated after vitamin D treatment. In this study, metabolic studies (e.g., tandem mass spectrometry, urine organic acid analysis, quantitative amino acid analysis in plasma, lactate, pyruvate, vitamin B12, homocysteine) to rule out inborn errors of metabolism and genetic studies (e.g., cardiomyopathy gene panel) to rule out genetic causes could not be done. Metabolic and genetic predispositions may cause the development of DCM in some patients. In the near future, the etiology will be further enlightened by new generation DNA sequencing tests.

\section{Conclusion}

Despite abundance of sunlight in Middle East and Egypt, this study revealed negative significant correlation between vitamin D level and FS and LVEDD in children with DCM, thus assessment of vitamin D level in children with idiopathic DCM is recommended, and prompt vitamin D supplementation in case of low level of vitamin $D$ could have positive effect on cardiac function.

\section{Ethical Approval}

The study was approved by the ethics committee of the Faculty of Medicine, Assiut University (IRB no: 17300487). Written informed consents were taken from parents with explanation of benefits of the study; risks expected and suggested treatment for each case.

\section{Authors' Contributions}

All authors read and approved the final manuscript. O.E.-A, N.O., and D.R. designed the study, literature search, interpreted the data, and wrote the manuscript. D.R. did echocardiography for all studied cases. M.D. did statistical analysis, share in literature search and writing. A.M. did all laboratory work in addition to interpretation of data.

\section{Funding \\ None. \\ Conflict of Interest \\ None declared}

\section{References}

1 Maron BJ, Towbin JA, Thiene G, et al; American Heart Association Council on Clinical Cardiology, Heart Failure and Transplantation Committee Quality of Care and Outcomes Research and Functional Genomics and Translational Biology Interdisciplinary Working Groups Council on Epidemiology and Prevention. Contemporary definitions and classification of the cardiomyopathies: an American Heart Association scientific statement from the council on clinical cardiology, heart failure and transplantation committee; quality of care and outcomes research and functional genomics and translational biology interdisciplinary working groups; and council on epidemiology and prevention. Circulation 2006;113(14):1807-1816

2 Richardson P, McKenna W, Bristow M, et al. Report of the 1995 World Health Organization/International Society and Federation of Cardiology Task Force on the definition and classification of cardiomyopathies. Circulation 1996;93(05):841-842

3 Puggia I, Merlo M, Barbati G, et al. Natural history of dilated cardiomyopathy in children. J Am Heart Assoc 2016;5(07): e003450

4 Cox GF, Sleeper LA, Lowe AM, et al. Factors associated with establishing a causal diagnosis for children with cardiomyopathy. Pediatrics 2006;118(04):1519-1531

5 Mor A, Karoli R. Study of vitamin D status in dilated cardiomyopathy at a North India. Age Years 2016;52(05):50-53

6 Holick MF. High prevalence of vitamin D inadequacy and implications for health. In Mayo Clinic Proceedings. Elsevier2006

7 Gupta DK, Wang TJ. Looking for a brighter future in heart failure: a role for vitamin D supplementation? J Am Coll Cardiol 2016;67 (22):2604-2606 
8 Chen S, Law CS, Grigsby CL, et al. Cardiomyocyte-specific deletion of the vitamin D receptor gene results in cardiac hypertrophy. Circulation 2011;124(17):1838-1847

9 Babu, P., and F. Damda. "G77 A Case of Dilated Cardiomyopathy Due to Nutritional Vitamin D Deficiency Rickets." Archives of Disease in Childhood 98. Suppl 1 2013:A39-A40http://dx.doi.org/ 10.1136/archdischild-2013-304107.089

10 Eren E, Abuhandan M, Güzel B, Koca B, Başpınar O. A treatable cause of cardiomyopathy: vitamin D deficiency. Güncel Pediatri 2015;13(02):143-146

11 Yilmaz O, Olgun H, Ciftel M, et al. Dilated cardiomyopathy secondary to rickets-related hypocalcaemia: eight case reports and a review of the literature. Cardiol Young 2015;25(02):261-266

12 Sanyal D, Raychaudhuri M. Infants with dilated cardiomyopathy and hypocalcemia. Indian J Endocrinol Metab 2013;17(Suppl 1): S221-S223

13 Zittermann A, Schleithoff SS, Tenderich G, Berthold HK, Körfer R, Stehle P. Low vitamin D status: a contributing factor in the pathogenesis of congestive heart failure? J Am Coll Cardiol 2003;41(01): 105-112

14 Priya S, Siddiqi Z, Karoli R, Fatima J, Gupta S, Mishra R. Study of vitamin $\mathrm{D}$ status in patients with dilated cardiomyopathy at a teaching hospital in North India. J Cardiovasc Echogr 2016;26 (03):89-93

15 Liu L, Chen M, Hankins SR, et al; Drexel Cardiovascular Health Collaborative Education, Research, and Evaluation Group. Serum 25-hydroxyvitamin D concentration and mortality from heart failure and cardiovascular disease, and premature mortality from allcause in United States adults. Am J Cardiol 2012;110(06):834-839

16 De Boland AR, Boland RL. Non-genomic signal transduction pathway of vitamin D in muscle. Cell Signal 1994;6(07):717-724

17 Souberbielle J-C, Body JJ, Lappe JM, et al. Vitamin D and musculoskeletal health, cardiovascular disease, autoimmunity and cancer: recommendations for clinical practice. Autoimmun Rev 2010;9 (11):709-715

18 Schierbeck LL, Jensen TS, Bang U, Jensen G, Køber L, Jensen JE. Parathyroid hormone and vitamin D-markers for cardiovascular and all cause mortality in heart failure. Eur J Heart Fail 2011;13 (06):626-632

19 Yeşilbaş O, Epçaçan S. Occurrence of nutritional hypocalcaemic rickets-related dilated cardiomyopathy in a child with concomitant rickets and infantile-onset Pompe disease. Cardiol Young 2019;29(03):425-427

20 Lang RM, Bierig M, Devereux RB, et al; American Society of Echocardiography's Nomenclature and Standards Committee Task Force on Chamber Quantification American College of Cardiology Echocardiography Committee American Heart Association European Association of Echocardiography, European Society of Cardiology. Recommendations for chamber quantification. Eur J Echocardiogr 2006;7(02):79-108
21 Holick MF. Vitamin D deficiency. N Engl J Med 2007;357(03): 266-281

22 Holick MF, Binkley NC, Bischoff-Ferrari HA, et al; Endocrine Society. Evaluation, treatment, and prevention of vitamin D deficiency: an Endocrine Society clinical practice guideline. J Clin Endocrinol Metab 2011;96(07):1911-1930

23 Ross AC, Manson JE, Abrams SA, et al. The 2011 report on dietary reference intakes for calcium and vitamin $D$ from the Institute of Medicine: what clinicians need to know. J Clin Endocrinol Metab 2011;96(01):53-58

24 Green RJ, Samy G, Miqdady MS, et al. Vitamin D deficiency and insufficiency in Africa and the Middle East, despite year-round sunny days. S Afr Med J 2015;105(07):603-605

25 Abu Shady MM, Youssef MM, Salah El-Din EM, et al. Predictors of serum 25-hydroxyvitamin D concentrations among a sample of Egyptian school children. ScientificWorldjournal 2016; 2016:8175768

26 van Ballegooijen AJ, Reinders I, Visser M, Brouwer IA. Parathyroid hormone and cardiovascular disease events: a systematic review and meta-analysis of prospective studies. Am Heart J 2013;165 (05):655-664, 664.e1-664.e5

27 Ameri P, Ronco D, Casu M, et al. High prevalence of vitamin D deficiency and its association with left ventricular dilation: an echocardiography study in elderly patients with chronic heart failure. Nutr Metab Cardiovasc Dis 2010;20 (09):633-640

28 Fuster Siebert M, Novo Rodríguez I, Castro-Gago M, Cabanas Gancedo R. Rachitic cardiomyopathy [in Spanish]. Med Clin (Barc) 1983;80(08):386-387

29 Olgun H, Ceviz N, Ozkan B. A case of dilated cardiomyopathy due to nutritional vitamin D deficiency rickets. Turk J Pediatr 2003;45 (02):152-154

30 Kosecik M, Ertas T. Dilated cardiomyopathy due to nutritional vitamin D deficiency rickets. Pediatr Int 2007;49(03):397-399

31 Maiya S, Sullivan I, Allgrove J, et al. Hypocalcaemia and vitamin D deficiency: an important, but preventable, cause of life-threatening infant heart failure. Heart 2008;94(05):581-584

32 Brown J, Nunez S, Russell M, Spurney C. Hypocalcemic rickets and dilated cardiomyopathy: case reports and review of literature. Pediatr Cardiol 2009;30(06):818-823

33 Jammal Addin MB, Young D, McCarrison S, Hunter L. Dilated cardiomyopathy in a national paediatric population. Eur J Pediatr 2019;178(08):1229-1235

34 Avsar A, Dogan A, Tavli T. A rare cause of reversible dilated cardiomyopathy: hypocalcemia. Echocardiography 2004;21(07): 609-612

35 Witte KK, Byrom R, Gierula J, et al. Effects of vitamin D on cardiac function in patients with chronic HF: the VINDICATE study. J Am Coll Cardiol 2016;67(22):2593-2603 